\title{
Characterization of three putative Lon proteases of Thermus thermophilus HB27 and use of their defective mutants as hosts for production of heterologous proteins
}

\author{
Tomoko Maehara, Takayuki Hoshino and Akira Nakamura
}

Division of Integrative Environmental Sciences, Graduate School of Life and Environmental Sciences, University of Tsukuba, 1-1-1 Tennodai, Tsukuba, Ibaraki 305-8572, Japan

Corresponding author: Nakamura A, a-nak@agbi.tsukuba.ac.jp

Phone/Fax: +81 298536637

Abbreviations: AAA + , ATPase associated with various cellular activities; ORF, open reading frame; IPTG, isopropyl- $\beta$-D-thiogalactopyranoside; EcLon, Lon protease of E. coli; TtLon, Lon protease of $T$. thermophilus; SDS-PAGE, SDS-polyacrylamide gel electrophoresis; 5-FOA, 5-fluoroorotic acid; Glt-AAF-MNA, glutaryl-Ala-Ala-Phe-methoxynaphthylamide; Suc-FLF-MNA, succinyl-Phe-Leu-Phe-methoxynaphthylamide; Thr-DH, threonine dehydrogenase; $\alpha$-Man, $\alpha$-mannosidase; Glu-DH, glutamate dehydrogenase; $\alpha$-amy, $\alpha$-amylase. 


\section{Abstract}

In the genome of a thermophilic bacterium, Thermus thermophilus HB27, three genes, TTC0418, TTC0746 and TTC1975, were annotated as ATP-dependent protease La (Lon). Sequence comparisons indicated that TTC0418 and TTC0746 showed significant similarities to bacterial LonA-type proteases, such as Escherichia coli Lon protease, especially in regions corresponding to domains for ATP-binding and hydrolysis, and for proteolysis, but TTC1975 exhibited a similarity only at the C-terminal proteolytic domain. The enzymatic analyses, using purified recombinant proteins produced by E. coli, revealed that TTC0418 and TTC0746 exhibited peptidase and protease activities against two synthetic peptides and casein, respectively, in an ATP-dependent manner; and at the same time, both the enzymes had significant ATPase activities in the presence of substrates. On the other hand, TTC1975 possessed a protease activity against casein, but addition of ATP did not enhance this activity. Moreover, a T. thermophilus mutant deficient in both TTC0418 and TTC0746 showed a similar growth characteristic to an E. coli lon mutant, i.e., a long growth lag after a nutritional downshift. These results indicate that TTC0418 and TTC0746 are actually members of bacterial LonA-type proteases with different substrate specificities, whereas TTC1975 should not be classified as a Lon protease. Finally, the effects of mutations deficient in these proteases were assessed on production of several heterologous gene products from Pyrococcus horikoshii and Geobacillus stearothermophilus. It was shown that TTC0746 mutation was more effective in improving production than the other two mutations, especially for production of $P$. horikoshii $\alpha$-mannosidase and G. stearothermophilus $\alpha$-amylase, indicating that the TTC0746 mutant of T. thermophilus HB27 may be useful for production of heterologous proteins from thermophiles and hyperthermophiles.

Key words: Thermus thermophilus, Lon protease, protease/peptidase, ATPase, heterologous gene-expression 


\section{Introduction}

An ATP-dependent protease, Lon, was first identified in Escherichia coli (Swamy and Goldberg 1981), and later in many organisms, from bacteria to eukaryotic mitochondria. The Lon protease family can be divided into two subfamilies, LonA and LonB, mainly based on the sources and the domain structures of the proteins (Rotanova et al. 2004). LonA is a bacterial and eukaryotic enzyme composed of three conserved domains: the N-terminal "N-domain," possibly related to substrate recognition (Ebel et al. 1999), the "AAA+ domain" at the center of the protein, responsible for ATPase activities (Fischer and Glockshuber 1994), and the C-terminal "P-domain" responsible for protease activities (Goldberg et al. 1994). LonB is an archaeal protein and consists of only the latter two domains. Of the Lon proteases, LonA of E. coli and LonB of Thermoplasma acidophilum have been enzymatically well characterized, e.g., catalytic residues for proteolysis (Starkova et al. 1998; Besche and Zwickl 2004; Rotanova et al. 2004), residues for ATP binding and hydrolysis, and three-dimensional structures (Besche et al. 2004; Botos et al. 2004; Rotanova et al. 2006). Physiologically, they are known to contribute to protein quality control in the cells, as well as regulating many cellular processes, by determining the fates of short-lived proteins (Goldberg 1992; Gottesman and Maurizi 1992; Gottesman 1996; Wicker et al. 1999). The Lon protease was also reported to degrade heterologous gene-products in E. coli (Buell et al. 1985; Miyamoto et al. 1985; Brodin et al. 1986; Walker et al. 1990; Alexander et al. 1992; Singh et al. 1992; Hutter and Singh 1998; Philibert and Martineau 2004).

In addition to these two subfamilies of Lon proteases, there are ORFs in some bacterial genomes showing certain similarities to Lon proteases, such as b0955 (YcbZ) of E. coli K-12 MG1655, which were annotated as "putative ATP-dependent proteases" or "Lon-like ATP-dependent proteases." These were classified as "bacterial LonB" by Maupin-Furlow et al. (2000), but enzymatic characterization of these ORFs, with respect to protease and ATPase activities, has not yet been reported.

We have recently developed a host-vector system for Thermus thermophilus HB27 (Maseda and Hoshino 1998; Takayama et al. 2004; Nakamura et al. 2005), an extremely thermophilic, Gram-negative bacterium growing between 50 and $82{ }^{\circ} \mathrm{C}$ (Oshima and Imahori 1974), and used it to test for expression of heterologous genes from a hyperthermophilic archaeon, Pyrococcus horikoshii. We succeeded in detecting corresponding activities of PH0655, PH0835 and PH1593 genes, encoding threonine dehydrogenase, $\alpha$-mannosidase, and glutamate dehydrogenase, respectively, when these genes were expressed under the control of strong promoters of $T$. thermophilus, P31 (Maseda and Hoshino 1995) and Pslp (Faraldo et al. 1992); however, the 
amounts of the products were low: no overproduced proteins corresponding to their gene products were detected on an SDS-PAGE gel by Coomassie blue staining when total cellular proteins from the transformants were loaded. This is contrary to the result when an intrinsic gene, such as Tth DNA polymerase gene, was overexpressed in T. thermophilus (Moreno et al. 2005).

To improve the production of heterologous gene products, we have focused on genes encoding Lon proteases in T. thermophilus HB27: one of the Lon proteases may act to degrade the heterologous gene products, and therefore the production may be improved by mutations deficient in this protease. There are three genes annotated to "ATP-dependent proteases (Lon)" (putative TtLon) in the genome of T. thermophilus HB27: TTC0418, TTC0746 and TTC1975. Watanabe et al. (1999) reported that TTHA0770 of T. thermophilus HB8, whose amino acid sequence was 100\% identical to that of TTC0418, proved to exhibit ATP-dependent peptidase activity that is characteristic of Lon proteases, indicating that TTC0418 was a Lon protease. However, no biochemical analysis of TTC0746 and TTC1975, or physiological characterization of these three proteins, was conducted. Moreover, it is not known whether some of these proteins are responsible for degradation of heterologous gene products.

In this paper we describe the biochemical and physiological characterization of these three proteins, and also show the effects of gene disruption on the production of several heterologous gene products in T. thermophilus HB27. 


\section{Materials and methods}

Bacterial strains, plasmids and media

The bacterial strains used in this study are listed in Table 1. Plasmids pUC19 and pET21a Table 1 were used for construction of putative Ttlon mutants in T. thermophilus, and for production of the putative TtLon proteases in E. coli, respectively. Plasmids pT8s-P31-hph5 (Nakamura et al. 2005) and pINV (Tamakoshi et al. 1997) were sources of selection markers in T. thermophilus, hph5 encoding the thermostable hygromycin B phosphotransferase and pyrE gene of T. thermophilus encoding orotate phosphoribosyltransferase (Yamagishi et al. 1996), respectively. pT8s-Pslp (Takayama et al. 2004) was used for cloning an $\alpha$-amylase gene of Geobacillus stearothermophilus DY-5 in E. coli, and expression of the gene in T. thermophilus. pTEV-P31-PH0655, pTEV-P31-PH0835 and pTEV-P31-PH1593 were expression plasmids of PH0655, PH0835 and PH1593 genes of P. horikoshii in T. thermophilus (Takayama et al. 2004).

T. thermophilus strains were grown at $70{ }^{\circ} \mathrm{C}$ in a rich medium (TM) or a minimal medium (MM), as described previously (Koyama et al. 1986). When necessary, proline and/or uracil (50 $\mu \mathrm{g} / \mathrm{ml}$ each) were added to MM.

E. coli strains were grown in Luria-Bertani (LB) medium. Ampicillin (100 $\mu \mathrm{g} / \mathrm{ml})$, kanamycin $(20 \mu \mathrm{g} / \mathrm{ml})$ and hygromycin $(200 \mu \mathrm{g} / \mathrm{ml})$ were added to the medium when necessary.

Expression and protein-purification of putative Ttlon genes in E. coli

The ORFs of TTC0418, TTC0746 and TTC1975 genes were amplified by PCR with Pyrobest DNA polymerase (Takara), using genome DNA of T. thermophilus HB27 as a template and each of the following primer pairs: TTC0418-F, 5'-agttccatatgaaggactttctgcgectag-3', and TTC0418-R, 5'-agttcgcggccgcagcgeccacgccggggct-3'; TTC0746-F, 5'-ggaattccatatgctaccggaaaccatgcccg-3', and TTC0746-R, 5 '-agttcgcggecgcggcatgggccacgagct-3';

TTC1975-F, 5'-ggaattccatatgttccccatgcgggtcgc-3', and TTC1975-R, 5'-agttcgcggecgccttctcctcccegttctc-3', respectively. In the forward primers, the ATG sequences of the NdeI sites introduced correspond to the initiation codons of the ORFs, and in the reverse primers, the NotI sites were introduced instead of the termination codons. The PCR fragments were digested with NdeI and NotI and cloned in the respective sites of pET21a (Novagen, Madison, WI, USA), giving rise to plasmids pET21a-TTC0418, pET21a-TTC0746 and pET21a-TTC1975. In these constructs, the 6×His-tag sequences were fused in-frame with the ORFs at their C-termini. After correct construction was 
confirmed by sequencing with a CEQ2000XL DNA sequencer (Beckman), plasmids pET21a-TTC0746 and pET21a-TTC1975 were introduced into E. coli BL21(DE3), and pET21a-TTC0418 was introduced into strain BL21(DE3) pLysS (Novagen, Madison, WI, USA).

E. coli strains harboring pET21a-TTC0418 and pET21a-TTC1975 were cultivated in LB medium until the early logarithmic growth phase, then $0.1 \mathrm{mM}$ IPTG was added to the cultures and cultivation was further continued for $4 \mathrm{~h}$ in the case of strains carrying pET21a-TTC0418 or for 20 $\mathrm{h}$ for pET21a-TTC1975. For the strain harboring pET21a-TTC0746, cultivation was conducted in the same way as that for the strain harboring pET21a-TTC1975, but without IPTG addition. The cells cultured in this way were collected by centrifugation at 2,500 $\mathrm{xg}$ for $5 \mathrm{~min}$, washed with TE buffer, and suspended in $10 \mathrm{mM}$ Tris- $\mathrm{HCl}$ buffer, $\mathrm{pH}$ 7.5. The cells were then disrupted by sonication, and the cell debris was removed by centrifugation at 4,000 x g for $20 \mathrm{~min}$. The crude extracts thus obtained were incubated at $70{ }^{\circ} \mathrm{C}$ for $20 \mathrm{~min}$ to heat-denature the E. coli proteins. After centrifugation at $11,100 \times \mathrm{g}$ for $30 \mathrm{~min}$, the resultant supernatants were loaded onto a column of HiTrap Chelating HP $(0.7 \times 2.5 \mathrm{~cm}$; GE healthcare $)$ pre-equilibrated with $200 \mathrm{mM} \mathrm{NiCl}_{2}$, and the column was washed with $0.02 \mathrm{M}$ sodium phosphate buffer containing $0.5 \mathrm{M} \mathrm{NaCl}, \mathrm{pH}$ 7.4. The recombinant protein was eluted with the above buffer containing $0.5 \mathrm{M}$ imidazole, and again loaded onto a HiTrap Desalting column (1.6 x $2.5 \mathrm{~cm}$; GE healthcare) to remove imidazole, using a buffer of $50 \mathrm{mM}$ Tris-HCl, $\mathrm{pH}$ 7.5. Purification was monitored by SDS-PAGE stained with Coomassie brilliant blue.

Assay of Lon protease activity

Protease activity was determined by the method of Kunitz (1947) with casein as the substrate. Three hundred $\mu \mathrm{l}$ of purified enzyme in $50 \mathrm{mM}$ Tris-HCl, $\mathrm{pH} 7.5$, was added to $700 \mu 1$ of $2 \%$ casein in $50 \mathrm{mM}$ Tris- $\mathrm{HCl}$ buffer containing $10.7 \mathrm{mM} \mathrm{MgCl}_{2}, \mathrm{pH} \mathrm{7.5}$, and incubated at $70{ }^{\circ} \mathrm{C}$ for $20 \mathrm{~min}$. The reaction was then stopped by adding $1 \mathrm{ml}$ of $0.4 \mathrm{M}$ trichloroacetic acid (TCA). After 30 minute-incubation at room temperature, the supernatant was separated by centrifugation at $11,100 \times$ $\mathrm{g}$ for $20 \mathrm{~min}$ and its absorbance at $280 \mathrm{~nm}$ was measured. One unit of activity was defined as the amount of enzyme which catalyzed an increase at $A_{280}$ of 0.001 per min. under the above conditions. The reaction was conducted with or without $1 \mathrm{mM}$ ATP in the reaction mixture.

Peptidase activity was assayed using two fluorogenic peptides, succinyl-Phe-Leu-Phe-methoxynaphthylamide (Suc-FLF-MNA; Backem) and glutaryl-Ala-Ala-Phe-MNA (Glu-AAF-MNA; Sigma) (Waxman and Goldberg 1985; Watanabe et al. 1999). The purified enzymes $(1 \mu \mathrm{g})$ were mixed with $0.3 \mathrm{mM}$ fluorogenic peptides in a buffer of 50 
$\mathrm{mM}$ Tris- $\mathrm{HCl}, 7.5 \mathrm{mM} \mathrm{MgCl} 2, \mathrm{pH} 7.5$, with or without $1 \mathrm{mM}$ ATP and $0.1 \mathrm{mg} / \mathrm{ml}$ casein in a total volume of $200 \mu \mathrm{l}$. Reaction mixtures were incubated for $1 \mathrm{~h}$ at $70{ }^{\circ} \mathrm{C}$, after which the reaction was stopped by placing on ice, and the hydrolysis of the peptides was monitored by measuring the increase in fluorescence (excitation at $370 \mathrm{~nm}$; emission at $535 \mathrm{~nm}$ ), using a microplate reader (DTX880; Beckman Coulter). One unit of the activity was defined as the amount of the enzyme which released $1 \mathrm{nmol}$ of MNA per h under the assay conditions.

For determination of ATPase activity, the amounts of ATP in the reaction mixtures were measured before and after the reactions described above, using the luciferin-luciferase assay with a CheckLite 250 Plus kit (Kikkoman). One unit of activity was defined as the amount of enzyme which consumed $1 \mathrm{nmol}$ of ATP per $\mathrm{h}$ under the assay conditions.

Genetic manipulation of T. thermophilus

Transformation of T. thermophilus cells was performed as previously described (Koyama et al. 1986; Hoshino et al. 1993), and transformants were selected by $40 \mu \mathrm{g} / \mathrm{ml}$ of kanamycin at $60{ }^{\circ} \mathrm{C}, 40$ $\mu \mathrm{g} / \mathrm{ml}$ of hygromycin at $65{ }^{\circ} \mathrm{C}$ and $200 \mu \mathrm{g} / \mathrm{ml}$ of 5 -FOA at $70{ }^{\circ} \mathrm{C}$. Plasmid isolation was conducted by the alkali-lysis method (Sambrook and Russell 2001).

Construction of putative Ttlon mutants

TTC0418, TTC0746 and TTC1975 genes were PCR-amplified with primer pairs of TTC0418-Fh, 5'-agttcgtcgactgaaggactttctgcgc-3', and TTC0418-Rh, 5'-agttcgaattcctaagcgcccacgccgg-3'; TTC0746-Fh, 5'-agttcgtcgactgctaccggaaaccatg-3', and TTC0746-Rh, 5'-agttcgaattcctaggcatgggccacga-3'; TTC1975-Fh, 5'-agttcgtcgactgttccccatgcgggtc-3', and TTC1975-Rh, 5'-agttcgaattcttacttctctcccegt-3', in which SalI and EcoRI sites were added to the forward and reverse primers, respectively. The resultant PCR fragments were digested with SalI and EcoRI, and cloned into the respective sites of pUC19. After correct construction was confirmed by sequencing, the plasmids thus obtained were designated pUC19LON1, pUC19LON2 and pUC19LON3, respectively.

Next, each of the plasmids was digested with MscI, located in the middle of each ORF, and ligated with the hph5 cassette, obtained by PCR amplification from pT8s-P31-hph5 (Nakamura et al. 2005) with primers hph5-f, 5'-attcggcccaaggtttacaaaatcc-3', and hph5-r, 5'-aacgcatgctattcctttgcctcggacga-3'. The resultant plasmids were designated pULH1, pULH2 and pULH3, respectively. In the cases of pUC19LON1 and pUC19LON2, a DNA fragment containing 
the pyrE gene, which was obtained by PCR amplification from pINV (Tamakoshi et al. 1997) with primers pyrE-f, 5'-atggacgtcctggagcttta-3', and pyrE-r, 5'-ctagacctcctccaagggca-3', was also inserted at the same MscI site, giving rise to pULE1 and pULE2, respectively. The plasmids thus constructed were used to transform T. thermophilus strain TM104, a pyrE mutant of TH104, which was obtained by transformation of TH104 with genomic DNA of MT111 (Tamakoshi et al. 1999) and selection by 5-FOA resistance. After the transformants were selected on TM containing hygromycin B or MM without uracil for insertions of hph5 or pyrE, respectively, correct integration was confirmed by Southern hybridization (Sambrook and Russell 2001), using digoxigenin-labeled PCR fragments of TTC0418, TTC0746, or TTC1975 gene, and hph5 or pyrE gene as probes. Strains were designated TL101, TL102, TL103, TL104 and TL105 for those carrying TTC0418::hph5, TTC0746::hph5, TTC1975::hph5, TTC0418::pyrE and TTC0746::pyrE mutations, respectively. Double mutants TL012, TL023 and TL013, were obtained by transformation of TL105, TL105 and TL104 with genomic DNA of TL101, TL103 and TL103, respectively (Table 1).

Growth tests of the mutants

The strain TM104 and its putative lon mutants were cultured in liquid TM at $65{ }^{\circ} \mathrm{C}$ overnight, inoculated into fresh TM or MM supplemented with proline and uracil (MM-PU), and the cultures were continued at $65{ }^{\circ} \mathrm{C}$. Growth of the strains was monitored by following the optical density at $600 \mathrm{~nm}$.

For a nutritional downshift experiment, the strains were cultivated in liquid TM until the mid-logarithmic phase of growth, after which the cells were washed once with $0.85 \% \mathrm{NaCl}$, and inoculated in MM-PU, either supplemented with or without $0.2 \%$ casamino acid, to give a final O.D. at $600 \mathrm{~nm}$ of 0.4 . Culturing was continued at $65^{\circ} \mathrm{C}$ and the growth of the strains was monitored.

Construction of plasmid pTEV-Pslp- $\alpha$-amy

An $\alpha$-amylase gene of Geobacillus stearothermophilus DY-5 (Tsukagoshi et al. 1984) was amplified by PCR with Ex-Taq DNA polymerase (Takara), using the primer pair of Amy-sigf, 5'-tacatgcatatgctaacgtttcaccgcatcat-3', and Amy-matr, 5'-tacatggcatgccgcaggcatcaaggccatgc-3'. In the forward primer, the ATG sequence of the NdeI site introduced corresponds to the initiation codon, and in the reverse primer, the SphI site was introduced just downstream of the termination codon. The PCR fragment was digested with NdeI and SphI, and cloned into the respective sites of pT8s-Pslp (Takayama et al. 2004), giving rise to plasmid pT8s-Pslp- $\alpha$-amy. After the nucleotide 
sequence had been confirmed by DNA sequencing, the plasmid was used to transform $T$. thermophilus TH104 (pTT8). Through a homologous recombination event between pTT8 and pT8s-Pslp- $\alpha$-amy in the cells, the plasmid pTEV-Pslp- $\alpha$-amy, replicable in T. thermophilus, was obtained (Hoshino et al. 1993).

Expression of heterologous genes in T. thermophilus mutants

Strain TM104 and its putative Ttlon mutants described above were transformed with pTEV-P31 plasmids harboring PH0655, PH0835 and PH1593 genes of P. horikoshii (Takayama et al 2004), and pTEV-Pslp- $\alpha$-amy, and cultured in liquid TM containing $40 \mu \mathrm{g} / \mathrm{ml}$ of kanamycin at 60 ${ }^{\circ} \mathrm{C}$ for $18 \mathrm{~h}$. Cells were collected by centrifugation at $5,800 \times \mathrm{g}$ for $10 \mathrm{~min}$ and washed with $0.85 \%$ $\mathrm{NaCl}$. The cells were then suspended in $50 \mathrm{mM}$ Tris-HCl, pH 7.0, and subjected to sonication. After cell debris had been removed by centrifugation $\left(11,100 \times \mathrm{g}, 25 \mathrm{~min}, 4^{\circ} \mathrm{C}\right)$, the supernatants obtained were used for corresponding enzyme assays.

Enzyme assays of heterologous gene products

Thr-DH, $\alpha$-Man and Glu-DH activities in the crude extracts of strains harboring the respective P. horikoshii genes were assayed as described previously (Takayama et al. 2004), and the enzyme activities were expressed as units per mg of total protein. Protein concentration of crude extracts was estimated using a protein assay kit (Bio-Rad, CA, USA) with bovine serum albumin as the standard.

For measurement of $\alpha$-amylase activity, crude extracts $(200 \mu 1)$ of strains harboring pTEV-Pslp- $\alpha$-amy were mixed with $500 \mu \mathrm{l}$ of $50 \mathrm{mM}$ Tris-HCl, $\mathrm{pH} 7.0$, containing $0.25 \%$ starch. After a 10-min incubation at $65{ }^{\circ} \mathrm{C}$, total released reducing sugar was determined by the dinitrosalicylic acid method (Miller 1959). One unit of the activity was defined as the amount of enzyme which liberated $1 \mu \mathrm{mol}$ of reducing sugar estimated as glucose per min. under the above conditions. 


\section{Results and discussion}

Comparison of amino acid sequences of three putative TtLons of strain HB27 with the related sequences

In the genome sequence of T. thermophilus HB27, three genes, TTC0418, TTC0746 and TTC1975, were annotated as ATP-dependent protease La (Lon). Comparison of amino acid sequences of these ORFs with that of E. coli Lon protease (EcLon) revealed that TTC0418 and TTC0746 showed moderate similarities to EcLon in overall length, the identities of which were $51.4 \%$ and $48.2 \%$, respectively (Fig. 1A). Of the three domains conserved among Lon protease family proteins, regions corresponding to the AAA+ and P-domains were highly conserved in TTC0418 and TTC0746. Moreover, motifs and residues required for substrate binding or catalysis in the AAA+ domain, such as the Walker A and B motifs, the Sensor-1 and 2 motifs, and the R-finger (Iyer et al. 2004), as well as the catalytic residues in the P-domain, Ser679 and Lys722 in EcLon numbering, were specifically conserved, indicating that these regions might have similar functions to those of $E c$ Lon.

Contrary to the above, the amino acid sequence of TTC1975 showed only a limited similarity to that of EcLon; the overall identity was $19.3 \%$ and significant conservation was observed only in the P-domain (Fig. 1). In a phylogenetic analysis based on the amino acid sequence of TTC1975 and those of proteins showing similarities to TTC0418 or TTC1975 sequence from the KEGG genome database, TTC1975 was included in a monophyletic cluster of bacterial proteins annotated to "putative ATP-dependent proteases" or "Lon-like proteases", or the so-called "bacterial LonB" subfamily (Maupin-Furlow et al. 2000), a representative of which was E. coli b0955 (YcbZ) (Fig. 1B). All of these proteins in this cluster also shared a similarity in the P-domain to the Lon proteases: notably, the regions around the catalytic residues of Lon proteases were highly conserved. On the other hand, regions other than the P-domain of these proteins did not show any similarities to the Lon proteases, including the AAA+ domain.

From these observations it was suggested that, in addition to TTC0418, which was previously identified as a Lon protease in strain HB8 (Watanabe et al. 1999), TTC0746 also functions as a Lon protease in T. thermophilus, i.e., an ATP-dependent protease, but TTC1975 may not require ATP for its proteolytic activity if the protein possesses such activity. To investigate the function of these proteins in more detail, enzymatic and functional analyses were conducted.

Enzymatic characterization of the putative TtLon proteases 
The three putative Ttlon genes were expressed in E. coli, using pET21a as a vector, and the protein products were purified by heat treatment at $70{ }^{\circ} \mathrm{C}$ for $20 \mathrm{~min}$. and affinity chromatography against the 6xHis-tag attached to the C-termini of the proteins. The purified proteins showed single bands on SDS-PAGE, with expected molecular weights of 89,90 and $77 \mathrm{kDa}$ for TTC0418, TTC0746 and TTC1975, respectively (Fig. 2).

Protease activities of these three proteins were first examined at $70{ }^{\circ} \mathrm{C}$ with casein as a substrate, in either the presence or the absence of $1 \mathrm{mM}$ ATP. At the same time, ATPase activities of the proteins were also measured in the presence or the absence of $2 \%$ casein. As shown in Table 2, all three proteins showed some proteolytic activity in the absence of ATP, with TTC1975 showing fairly strong activity. When ATP was added to the reaction mixtures, the activity of TTC0746 was enhanced about 10-fold, but those of TTC0418 and TTC1975 were not affected. In addition to the above observation, apparent ATPase activity was detected only when TTC0746 was incubated with the protease substrate. These results clearly indicate that TTC0746 exhibits protease activity with concomitant hydrolysis of ATP. On the other hand, TTC0418 and TTC1975 did not show ATP-dependency of their protease activities. The results of TTC0418 are contrary to the previous results of Watanabe et al. (1999); they demonstrate that the same protein to TTC0418 from the strain HB8, TTHA0770, exhibited ATP-dependent peptidase activity against two synthetic peptides.

We thought that this discrepancy might be derived from the substrates used: casein and the synthetic peptides. To test this possibility, and also to analyze the properties of the activities of TTC0746 and TTC1975 in more detail, we next measured the peptidase activities of the three proteins, using two synthetic peptides similar to those Watanabe et al. used. It should be noted that one of the peptides we used, Glt-AAF-MNA, was different from that Watanabe et al. used in its protecting group at the $\mathrm{NH}_{2}$-terminus. As expected, TTC0418 clearly showed ATP-dependent peptidase activity; the activities toward Suc-FLF-MNA and Glt-AAF-MNA were enhanced by the addition of ATP by about 30- and 15-fold, respectively. At the same time, TTC0418 exhibited ATPase activity only when the peptide substrate was present. Watanabe et al. reported that TTHA0770 exhibited stronger activity toward Suc-FLF-MNA than Suc-AAF-MNA about 14-fold, but in our result, no such substrate specificity was observed. The precise reason for this discrepancy is not known, but it may be derived from differences in the assay conditions, or that the difference in the protecting groups of the substrates used affected substrate recognition of the enzyme.

When compared to TTC0418, TTC0746 showed similar peptidase activities toward both substrates in the absence of ATP, and a weak but distinct activation of about 2.4-fold by the addition of ATP was detected on both substrates. On the other hand, TTC1975 exhibited a rather weak 
peptidase activity toward the substrates that was not affected by the addition of ATP. As for ATPase activity, TTC0746 exhibited the activity under the same conditions as TTC0418 did, but TTC1975 did not, in either the presence or absence of the substrate.

In EcLon and TTHA0770, it was reported that addition of $0.1 \mathrm{mg} / \mathrm{ml}$ casein to the reaction mixtures enhanced their peptidase and ATPase activities (Waxman and Goldberg 1986; Watanabe et al. 1999). We observed similar enhancement in TTC0418 reactions. In the case of TTC0746, its peptidase activity toward Suc-FLF-MNA was not affected by addition in the absence of ATP; but in the presence of ATP, a two-fold enhancement was observed. At the same time, the ATPase activity was also enhanced about two-fold (data not shown). On the other hand, the peptidase activity of TTC1975 was not affected by the addition.

From these observations, we concluded that, in addition to TTC0418, TTC0746 was apparently an ATP-dependent protease and could be classified as a Lon protease, as suggested by its sequence similarity to EcLon. Therefore, we hereinafter renamed TTC0418 as TtLonA1 and TTC0746 as TtLonA2. The difference in protease and peptidase activities that TtLonA1 and $T t$ LonA2 showed may reflect differences in the substrate specificity of the enzymes. On the other hand, TTC1975 possessed apparent protease activity, but this activity was not affected by the addition of ATP, nor was ATPase activity detected. Taken together with the loss of the sequence similarity of TTC1975 at the region corresponding to the AAA+ domain, we concluded that this protein was an ATP-independent protease, and therefore should not be classified as a Lon protease.

Physiological characterization of Ttlon mutants

It has been reported that an Eclon mutant shows a characteristic growth phenotype: it grows normally in a rich medium, but shows an extended growth lag after transition to a minimal medium, possibly due to low availability of free amino acids caused by less efficient protein turnover (Kuroda et al. 2001). To test whether mutants deficient in TtLonA1, TtLonA2, or TTC1975, or their double mutant show a similar phenotype to the Eclon mutant, we constructed knock-out mutants as described in Materials and methods, and observed their growth in TM and MM, and after transition from TM to MM (nutritional downshift). As shown in Fig. 3, the growth of all single mutants deficient in either TtLonA1, TtLonA2 or TTC1975, and two double mutants deficient in either TtLonA1 or TtLonA2, and TTC1975, was indistinguishable from that of their parental strain, both in TM and MM, whereas a TtlonA1 TtlonA2 double mutant, TL102, showed a slight delay in growth in TM (Fig. 3A), and severe growth defects in MM (Fig. 3B). Also, this strain showed the same growth defects after nutritional downshift (Fig. 3C); the growth did not restore even after the 
cultivation was continued for overnight at $65{ }^{\circ} \mathrm{C}$ (data not shown). Addition of $0.2 \%$ casamino acid to MM restored the growth of the mutant, indicating that the growth defect of the mutant was due to low availability of free amino acids, like that observed in the Eclon mutant.

These results suggest that TtLonA1 and TtLonA2 function in the same way as EcLon in vivo, i.e., regulation of intracellular protein turnover upon nutritional downshift. In spite of the difference in the substrate specificities observed above, these two enzymes seem likely to have the same function, or a redundant function, since neither a TtlonA1 nor TtlonA2 single mutation affected the growth of the mutants, at least under these conditions. Moreover, the TTC1975 mutation, either in combination with the TtlonA1 or TtlonA2 mutation, did not show any effects on growth, indicating that this enzyme's function is not the same as that of Lon proteases.

Effect of lon mutations on the production of heterologous gene products

Finally, to investigate whether the introduction of the TtlonA1, TtlonA2 or TTC1975 mutation can improve production of heterologous gene products, we introduced three reference genes from Pyrococcus horikoshii, PH0655, PH0835 and PH1593 genes encoding threonine dehydrogenase (Thr-DH), $\alpha$-mannosidase ( $\alpha$-Man) and glutamate dehydrogenase (Glu-DH), respectively, and an $\alpha$-amylase ( $\alpha$-amy) gene from Geobacillus stearothermophilus, to strain TM104 and its mutants described above, using a pTEV plasmid replicable in T. thermophilus. The introduced genes were expressed under the control of P31 or Pslp promoter, and the corresponding enzyme activities were measured in cell extracts of the transformants, as described in Materials and methods. It is notable that the $\alpha$-amy is an extracellular enzyme in $G$. stearothermophilus, but its activity was not detected in the cultural broth when this gene was expressed in T. thermophilus (data not shown), indicating that the enzyme was produced in the intracellular fraction or in the periplasmic space of the cells. Also, it should be noted that each of the four enzyme activities detected in the cell extracts of the strain TM104 containing the vector plasmid, pTEV-P31 or pTEV-Pslp, was less than 5\% of that detected in the extracts of the same strain expressing the respective heterologous gene (Table 3 ), indicating that most of the activities in strains expressing the heterologous genes were derived from the heterologous proteins produced, not from proteins of the host strains.

As shown in Table 3, introduction of the TtlonA2 mutation somewhat improved the production of all four proteins: notably, about a two-fold increase was observed in the production of the $\alpha$-Man. On the other hand, TtlonA1 or TTC1975 mutation had no, or somewhat negative, effects on the production of all the enzymes tested. In particular, the production of Thr-DH in both mutants and that of $\alpha$-Man in the TtlonA1 mutant sharply reduced to about half of that in the wild type strain. 
The precise reason why the production of the heterologous proteins was reduced in these mutants is not known, but from these results we conclude that only the TtlonA2 mutation is effective for production of heterologous proteins. The difference observed between TtlonA1 and TtlonA2 mutations may reflect the difference in the substrate specificities of the enzymes, since TtLonA2 preferred larger substrates such as casein (Table 2).

When TtlonA1 or TTC1975 mutation was combined with TtlonA2 mutation, the production of $\alpha$-amy was specifically improved, reaching about double the amount produced in the TtlonA2 mutant. Also, the production of this enzyme slightly increased in the TtlonA1 TTC1975 double mutant to about 1.5 -fold of that in the wild type strain. It may thus be possible that TtlonA1 or TTC1975 mutation was effective for production of a specific heterologous protein when it was combined with TtlonA2 mutation, or less efficiently, with each other.

In E. coli, strains deficient in EcLon were used to direct overproduction of several heterologous gene products (Buell et al. 1985; Miyamoto et al. 1985; Brodin et al. 1986; Walker et al. 1990; Alexander et al. 1992; Singh et al. 1992; Hutter and Singh 1998; Philibert and Martineau 2004). In some cases, the production was observed only in Eclon mutants, not in wild type strains. In the cases of bovine intestinal calcium binding protein and human somatomedin-C, it was reported that the production was enhanced about two to three fold by introduction of Eclon mutation (Buell et al. 1985; Brodin et al. 1986). Our results described herein, especially those with TtlonA2 mutants, were almost comparable with those with Eclon mutant. However, as any overproduced bands corresponding to the expressed gene products were not detected on an SDS-PAGE gel when the whole-cell extracts of the transformants described above were loaded (data not shown), it may be possible that other protease(s) produced by the host cells is responsible for degradation of the products.

In conclusion, we analyzed enzymatically the three putative lon genes in $T$. thermophilus HB27. The results indicated that, in addition to TTC0418 (TtLonA1), TTC0746 also exhibited an ATP-dependent protease activity with different substrate specificity from TtLonA1, and therefore should be classified as a Lon protease (TtLonA2). On the other hand, TTC1975 did not show ATPase activity or ATP-dependent activation of protease activity, but demonstrated significant protease activity, indicating that this enzyme should be classified as another type of protease, distinct from Lon protease. In addition, the TtlonA1 TtlonA2 double mutant showed a characteristic growth feature similar to an Eclon mutant, indicating that these two enzymes have a similar function to EcLon in vivo. Finally, we discovered that the TtlonA2 mutation is effective for improvement of production of several heterologous proteins in T. thermophilus. 
We are now conducting experiments to identify other proteases responsible for degradation of heterologous proteins by constructing mutant strains in which genes annotated to proteases or peptidases are disrupted, then using them as hosts for the expression of heterologous genes. 


\section{References}

Alexander DM, Hesson T, Mannarino A, Cable M, Dalie BL (1992) Isolation and purification of a biologically active human platelet-derived growth factor BB expressed in Escherichia coli. Protein Expr Purif 3:204-211

Besche H, Tamura N, Tamura T, Zwickl P (2004) Mutational analysis of conserved AAA+ residues in the archaeal Lon protease from Thermoplasma acidophilum. FEBS Lett 574:161-166

Besche H, Zwickl P (2004) The Thermoplasma acidophilum Lon protease has a Ser-Lys dyad active site. Eur J Biochem 271:4361-4365

Botos I, Melnikov EE, Cherry S, Tropea JE, Khalatova AG, Rasulova F, Dauter Z, Maurizi MR, Rotanova TV, Wlodawer A, Gustchina A (2004) The catalytic domain of Escherichia coli Lon protease has a unique fold and a Ser-Lys dyad in the active site. J Biol Chem 279:8140-8148

Brodin P, Grundström T, Hofmann T, Drakenberg T, Thulin E, Forsén S (1986) Expression of bovine intestinal calcium binding protein from a synthetic gene in Eshcherichia coli and characterization of the product. Biochemistry 25:5371-5377

Buell G, Schulz MF, Selzer G, Chollet A, Movva NR, Semon D, Escanez S, Kawashima E (1985) Optimizing the expression in E. coli of a synthetic gene encoding somatomedin-C (IGF-I). Nucleic Acids Res 13:1923-1938

Ebel W, Skinner MM, Dierksen KP, Scott JM, Trempy JE (1999) A conserved domain in Escherichia coli Lon protease is involved in substrate discriminator activity. J Bacteriol $181: 2236-2243$

Faraldo MM, de Pedro MA, Berenguer J (1992) Sequence of the S-layer gene of Thermus thermophilus HB8 and functionality of its promoter in Escherichia coli. J Bacteriol 174:7458-7462

Fischer H, Glockshuber R (1994) A point mutation within the ATP-binding site inactivates both catalytic functions of the ATP-dependent protease La (Lon) from Escherichia coli. FEBS Lett 356:101-103

Goldberg AL (1992) The mechanism and functions of ATP-dependent proteases in bacterial and animal cells. Eur J Biochem 203:9-23

Goldberg AL, Moerschell RP, Chung CH, Maurizi MR (1994) ATP-dependent protease La (lon) from Escherichia coli. Methods Enzymol 244:350-375

Gottesman S (1996) Proteases and their targets in Escherichia coli. Annu Rev Genet 30:465-506

Gottesman S, Maurizi MR (1992) Regulation by proteolysis: energy-dependent proteases and their targets. Microbiol Rev 56:592-621 
Hoshino T, Maseda H, Nakahara T (1993) Plasmid marker rescue transformation in Thermus thermophilus. J Ferment Bioeng 76:276-279

Hutter B, Singh M (1998) Host vector system for high-level expression and purification of recombinant, enzymatically active alanine dehydrogenase of Mycobacterium tuberculosis. Gene 212:21-29

Iyer LM, Leipe DD, Koonin EV, Aravind L (2004) Evolutionary history and higher order classification of AAA+ ATPases. J Struct Biol 146:11-31

Koyama Y, Hoshino T, Tomizuka N, Furukawa K (1986) Genetic transformation of the extreme thermophile Thermus thermophilus and of other Thermus spp. J Bacteriol 166:338-340

Kunitz M (1947) Crystalline soybean trypsin inhibitor, II. General properties. J Gen Physiol $30: 291-310$

Kuroda A, Nomura K, Ohtomo R, Kato J, Ikeda T, Takiguchi N, Ohtake H, Kornberg A (2001) Role of inorganic polyphosphate in promoting ribosomal protein degradation by the Lon protease in E. coli. Science 293:705-708

Marchler-Bauer A, Anderson JB, Derbyshire MK, DeWeese-Scott C, Gonzales NR, Gwadz M, Hao L, He S, Hurwitz DI, Jackson JD, Ke Z, Krylov D, Lanczycki CJ, Liebert CA, Liu C, Lu F, Lu S, Marchler GH, Mullokandov M, Song JS, Thanki N, Yamashita RA, Yin JJ, Zhang D, Bryant SH (2007) CDD: a conserved domain database for interactive domain family analysis. Nucleic Acids Res. 35:D237-240

Maseda H, Hoshino T (1995) Screening and analysis of DNA fragments that show promoter activities in Thermus thermophilus. FEMS Microbiol Lett 128:127-134

Maseda H, Hoshino T (1998) Development of expression vectors for Thermus thermophilus. J Ferment Bioeng 86:121-124

Maupin-Furlow JA, Wilson HL, Kaczowka SJ, Ou MS (2000) Proteasomes in the archaea: from structure to function. Front Biosci 5:D837-D865

Miller GL (1959) Use of dinitrosalicylic acid reagent for determination of reducing sugars. Anal Chem 31:426-428

Miyamoto C, Chizzonite R, Crowl R, Rupprecht K, Kramer R, Schaber M, Kumar G, Poonian M, Ju G (1985) Molecular cloning and regulated expression of the human c-myc gene in Escherichia coli and Saccharomyces cerevisiae: comparison of the protein products. Proc Natl Acad Sci USA 82:7232-7236

Moreno R, Haro A, Castellanos A, Berenguer J (2005) High-level overproduction of His-tagged Tth DNA polymerase in Thermus thermophilus. Appl Environ Microbiol 71:591-593

Nakamura A, Takakura Y, Kobayashi H, Hoshino T (2005) In vivo directed evolution for 
thermostabilization of Escherichia coli Hygromycin B phosphotransferase and the use of the gene as a selection marker in the host-vector system of Thermus thermophilus. J Biosci Bioeng 100:158-163

Oshima T, Imahori K (1974) Description of Thermus thermophilus (Yoshida and Oshima) comb. nov., a nonsporulating thermophilic bacterium from a Japanese thermal spa. Int J Syst Bacteriol 24:102-112

Page RD (1996) TREEVIEW: An application to display phylogenetic trees on personal computers. Comput Appl Biosci 12: 357-358

Philibert P, Martineau P (2004) Directed evolution of single-chain Fv for cytoplasmic expression using the $\beta$-galactosidase complementation assay results in proteins highly susceptible to protease degradation and aggregation. Microb Cell Fact 3:16

Rotanova TV, Melnikov EE, Khalatova AG, Makhovskaya OV, Botos I, Wlodawer A, Gustchina A (2004) Classification of ATP-dependent proteases Lon and comparison of the active sites of their proteolytic domains. Eur J Biochem 271: 4865-4871

Rotanova TV, Botos I, Melnikov EE, Rasulova F, Gustchina A, Maurizi MR, Wlodawer A (2006) Slicing a protease: Structural features of the ATP-dependent Lon proteases gleaned from investigations of isolated domains. Protein Sci 15:1815-1828

Sambrook J, Russell D (2001) Molecular cloning: a laboratory manual, 3rd ed. Cold Spring Harbor Laboratory Press, Cold Spring Harbor, New York

Singh M, Andersen AB, McCarthy JEG, Rohde M, Schütte H, Sanders E, Timmis KN (1992) The Mycobacterium tuberculosis 38-kDa antigen: overproduction in Escherichia coli, purification and characterization. Gene 117:53-60

Starkova NN, Koroleva EP, Rumsh LD, Ginodman LM, Rotanova TV (1998) Mutations in the proteolytic domain of Escherichia coli protease Lon impair the ATPase activity of the enzyme. FEBS Lett 422:218-220

Swamy KH, Goldberg AL (1981) E. coli contains eight soluble proteolytic activities, one being ATP dependent. Nature 292:652-654

Takayama G, Kosuge T, Sunamura S, Matsui I, Ishikawa K, Nakamura A, Hoshino T (2004) Use of a Thermus thermophilus host-vector system for expression of genes from the hyperthermophilic archaeon Pyrococcus horikoshii. J Jpn Soc Extremophiles 3:18-27

Tamakoshi M, Uchida M, Tanabe K, Fukuyama S, Yamagishi A, Oshima T (1997) A new Thermus-Escherichia coli shuttle integration vector system. J Bacteriol 179:4811-4814

Tamakoshi M, Yaoi T, Oshima T, Yamagishi A (1999) An efficient gene replacement and deletion system for an extreme thermophile, Thermus thermophilus. FEMS Microbiol Lett 
$173: 431-437$

Thompson JD, Gibson TJ, Plewniak F, Jeanmougin F, Higgins DG (1997) The CLUSTAL_X windows interface: flexible strategies for multiple sequence alignment aided by quality analysis tools. Nucleic Acids Res 25:4876-4882

Tsukagoshi N, Ihara H, Yamagata H, Udaka S (1984) Cloning and expression of a thermophilic $\alpha$-amylase gene from Bacillus stearothermophilus in Escherichia coli. Mol Gen Genet $193: 58-63$

Walker MJ, Rohde M, Brownlie RM, Timmis KN (1990) Engineering upstream transcriptional and translational signals of Bordetella pertussis serotype 2 fimbrial subunit protein for efficient expression in Escherichia coli: in vitro autoassembly of the expressed product into filamentous structures. Mol Microbiol 4:39-47

Watanabe S, Muramatsu T, Ao H, Hirayama Y, Takahashi K, Tanokura M, Kuchino Y (1999) Molecular cloning of the Lon protease gene from Thermus thermophilus HB8 and characterization of its gene product. Eur J Biochem 266:811-819

Waxman L, Goldberg AL (1985) Protease La, the lon gene product, cleaves specific fluorogenic peptides in an ATP-dependent reaction. J Biol Chem 260:12022-12028

Waxman L, Goldberg AL (1986) Selectivity of intracellular proteolysis: Protein substrates activate the ATP-dependent protease (La). Science 232:500-503

Wickner S, Maurizi MR, Gottesman S (1999) Posttranslational quality control: folding, refolding, and degrading proteins. Science 286:1888-1893

Yamagishi A, Tanimoto T, Suzuki T, Oshima T (1996) Pyrimidine biosynthesis genes (pyrE and pyrF) of an extreme thermophile, Thermus thermophilus. Appl Environ Microbiol 62:2191-2194

Yanisch-Perron C, Vieira J, Messing J (1985) Improved M13 phage cloning vectors and host strains: nucleotide sequences of the M13mp18 and pUC19 vectors. Gene 33:103-119 


\section{Figure legends}

Figure 1. Comparison of amino acid sequences of putative Lon proteases of T. thermophilus HB27 with related sequences.

a Amino acid sequences of EcLon (LON_ECOLI) and three putative Lon proteases of $T$. thermophilus HB27 (TTC0418, TTC0746 and TTC1975) were aligned using ClustalX software (Thompson et al. 1997). Conserved amino acids are shaded, and regions corresponding to three domains in EcLon, according to a conserved domain database in the NCBI homepage (http://www.ncbi.nlm.nih.gov/Structure/cdd/; Marchler-Bauer et al. 2007), are boxed. Circles indicate regions and a residue responsible for ATP binding and hydrolysis in the AAA+ domain. Asterisks in the P-domain indicate the catalytic residues for proteolysis. b Phylogenetic relationships of Lon proteases or Lon-like proteases from Bacteria and Archaea. Several amino acid sequences showing similarities to that of TTC0418 or TTC1975 were selected from the KEGG genome database (http://www.genome.ad.jp/en/gn_kegg.html), and the tree was constructed by neighbor-joining method using Clustal X software and visualized by Tree-view software (Page 1996). The names of organisms and accession numbers were indicated as KEGG organisms and accession numbers. EcLon, TTC0418, TTC0746 and TTC1975 were indicated by larger fonts with underlines.

Figure 2. SDS-PAGE of the purified recombinant proteins of three putative Lon proteases.

The purified proteins after affinity chromatography were loaded onto a $12.5 \%$ SDS-polyacrylamide gel. Lane M, molecular mass markers (values in left); 1, TTC0418; 2, TTC0746; 3, TTC1975.

Figure 3. Growth of T. thermophilus HB27 wild-type and lon mutants in TM (a), MM (b) and in MM after nutritional downshift (c).

Culture conditions are described in Materials and methods. Symbols: filled squares, TM104; open squares, TL101; filled triangles, TL102; open triangles, TL103; filled circles, TL012; open circles, TL023; diamonds, TL013; open and filled asterisks, TM104 and TL012 in MM supplemented with $0.2 \%$ casamino acids, respectively. 
Table 1 Bacterial strains used in this study

\begin{tabular}{|c|c|c|}
\hline Strains & Genotype & Reference or source \\
\hline \multicolumn{3}{|l|}{ T. thermophilus } \\
\hline TH104 (pTT8) & proC4 mutant of HB27 harboring pTT8 & Takayama et al. (2004) \\
\hline MT111 & $\Delta p y r E$ mutant of HB27 & Tamakoshi et al. (1999) \\
\hline TM104 & proC4 $\Delta$ pyrE & This study \\
\hline TL101 & proC4 $\triangle$ pyrE TTC0418: hph5 & This study \\
\hline TL102 & proC4 $\triangle$ pyrE TTC0746: hph5 & This study \\
\hline TL103 & proC4 $\Delta$ pyrE TTC1975: hph5 & This study \\
\hline TL104 & proC4 АpyrE TTC0418: pyrE & This study \\
\hline TL105 & proC4 $\triangle$ pyrE TTCO $746:$ pyrE & This study \\
\hline TL012 & proC4 $\triangle$ pyrE TTC0418: hph5 TTCO746: pyrE & This study \\
\hline TL023 & proC4 $\triangle$ pyrE TTC0746:pyrE TTC1975::hph5 & This study \\
\hline TL013 & proC4 $\triangle$ pyrE TTC0418::pyrE TTC1975::hph5 & This study \\
\hline \multicolumn{3}{|l|}{ E. coli } \\
\hline \multirow[t]{2}{*}{ JM109 } & \multicolumn{2}{|c|}{ 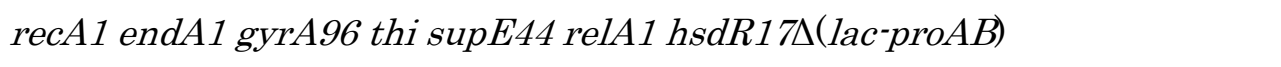 } \\
\hline & $\mathrm{F}^{\prime}($ traD36 pro $A B$ lacI IacZ $\Delta \mathrm{M} 15)$ & Yanisch-Perron et al. (1985) \\
\hline BL21(DE3) & $\mathrm{F}^{-}$ompT hsdSB $\left(r B^{-} m B^{-}\right)$gal dcm (DE3) & Novagen, Madison, WI, USA \\
\hline BL21(DE3) pLysS & BL21(DE3) harboring pLysS & Novagen, Madison, WI, USA \\
\hline
\end{tabular}


Table 2. Protease/peptidase and ATPase activities of the putative TtLon proteases

\begin{tabular}{|c|c|c|c|c|c|}
\hline \multirow[t]{2}{*}{ Substrate } & \multirow[t]{2}{*}{ Enzyme } & \multicolumn{2}{|c|}{ Protease or peptidase activity $(\mathrm{U} / \mathrm{mg})^{\mathrm{a}}$} & \multicolumn{2}{|c|}{ ATPase activity $(\mathrm{U} / \mathrm{mg})^{\mathrm{a}}$} \\
\hline & & $-\mathrm{ATP}^{\mathrm{b}}$ & $+\mathrm{ATP}^{\mathrm{b}}$ & -substrate & + substrate $^{\mathrm{c}}$ \\
\hline \multirow[t]{3}{*}{ Casein } & TTC0418 & $14.3 \pm 5.72$ & $10.0 \pm 4.04$ & $<50^{\mathrm{d}}$ & $<50$ \\
\hline & TTC0746 & $4.02 \pm 2.00$ & $47.2 \pm 11.1$ & $<50$ & $2.25 \times 10^{3} \pm 113$ \\
\hline & TTC1975 & $48.9 \pm 13.4$ & $57.6 \pm 21.3$ & $<50$ & $<50$ \\
\hline \multirow[t]{3}{*}{ Suc-FLF-MNA } & TTC0418 & $34.5 \pm 8.07$ & $1.07 \times 10^{3} \pm 71.1$ & $<2 \times 10^{2 \mathrm{e}}$ & $1.12 \times 10^{3} \pm 211$ \\
\hline & TTC0746 & $57.3 \pm 1.91$ & $136 \pm 37.6$ & $<2 \times 10^{2}$ & $7.84 \times 10^{2} \pm 75.2$ \\
\hline & TTC1975 & $37.1 \pm 10.9$ & $50.8 \pm 10.5$ & $<2 \times 10^{2}$ & $<2 \times 10^{2}$ \\
\hline \multirow[t]{3}{*}{ Glt-AAF-MNA } & TTC0418 & $71.7 \pm 9.50$ & $1.17 \times 10^{3} \pm 112$ & n.a. ${ }^{f}$ & n.a. \\
\hline & TTC0746 & $65.4 \pm 18.3$ & $157 \pm 21.1$ & n.a. & n.a. \\
\hline & TTC1975 & $9.54 \pm 0.313$ & $10.6 \pm 2.76$ & n.a. & n.a. \\
\hline
\end{tabular}

\footnotetext{
${ }^{a}$ Enzyme activities were assayed in triplicate, and expressed as mean \pm S.D.

${ }^{\mathrm{b}}$ The activities were assayed in the absence (-ATP) or the presence (+ATP) of 1 mM ATP.

c The activities were assayed in the absence (-substrate) or the presence (+substrate) of protease/peptidase substrates.

${ }^{\mathrm{d}, \mathrm{e}}$ Below the levels of detection under these assay conditions.

${ }^{\mathrm{f}}$ Not analyzed.
} 
Table 3 Comparison of heterologous enzyme activities expressed in T. thermophilus

\begin{tabular}{lcccc}
\hline Host strain & \multicolumn{4}{c}{ Enzyme activity (mU/mg protein)a } \\
\cline { 2 - 5 } & Thr-DH (PH0655) & a-Man (PH0835) & Glu-DH (PH1593) & a-amy \\
\hline TM104 & $11.4 \pm 3.90$ & $9.72 \pm 3.97$ & $322 \pm 41.5$ & $263 \pm 43.6$ \\
TL101 & $6.82 \pm 1.67$ & $6.81 \pm 2.87$ & $267 \pm 31.5$ & $88.6 \pm 21.6$ \\
TL102 & $12.7 \pm 5.31$ & $19.6 \pm 4.25$ & $418 \pm 73.0$ & $426 \pm 70.5$ \\
TL103 & $6.27 \pm 1.45$ & $7.93 \pm 3.33$ & $361 \pm 122$ & $237 \pm 73.3$ \\
TL012 & $7.17 \pm 2.14$ & $5.13 \pm 0.87$ & $213 \pm 77.5$ & $867 \pm 59.6$ \\
TL023 & $7.91 \pm 2.11$ & $20.0 \pm 4.09$ & $262 \pm 68.0$ & $735 \pm 149$ \\
TL013 & $5.00 \pm 0.46$ & $9.23 \pm 3.81$ & $233 \pm 47.5$ & $403 \pm 100$ \\
TM104/(control ${ }^{b)}$ & $0.98 \pm 0.11$ & $0.354 \pm 0.037$ & $12.1 \pm 3.00$ & $13.4 \pm 0.29$ \\
\hline
\end{tabular}

a Enzyme activities were measured in triplicate, and expressed as mean \pm S.D.

b Enzyme activities were assayed with crude extracts of T. thermophilus TM104 harboring vector plasmid pTEV-P31 for Thr-DH, $\alpha$-Man and Glu-DH activities, or pTEV-P slp for $\alpha$-amy activity. 


\section{$\mathrm{N}$-domain}

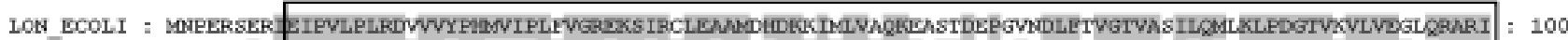

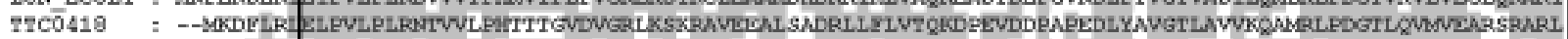

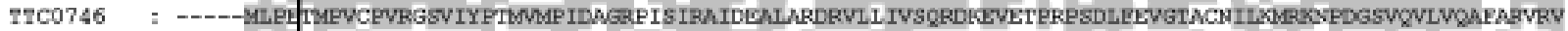

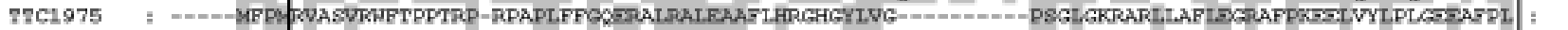

LON ECOLI 8700418 2500746 72C1975

LON ECOLI 7rc0 418

2700746 rac1975

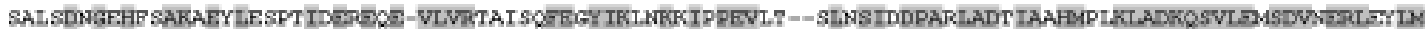

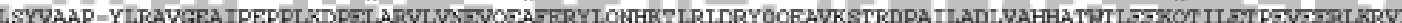

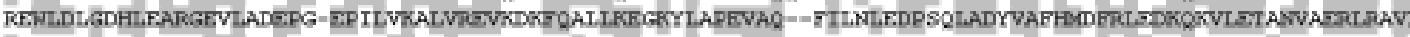

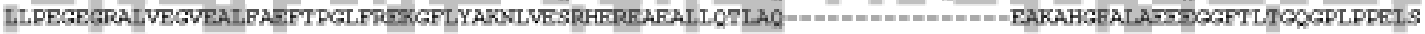

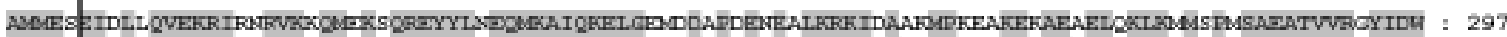

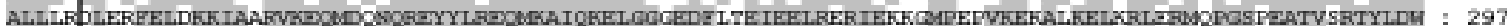

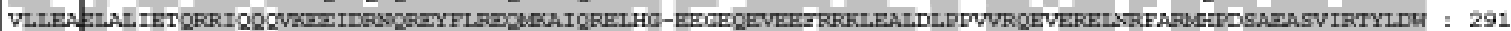

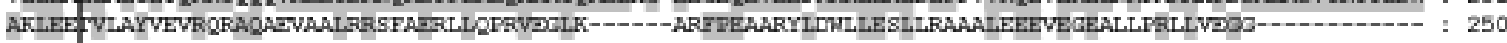

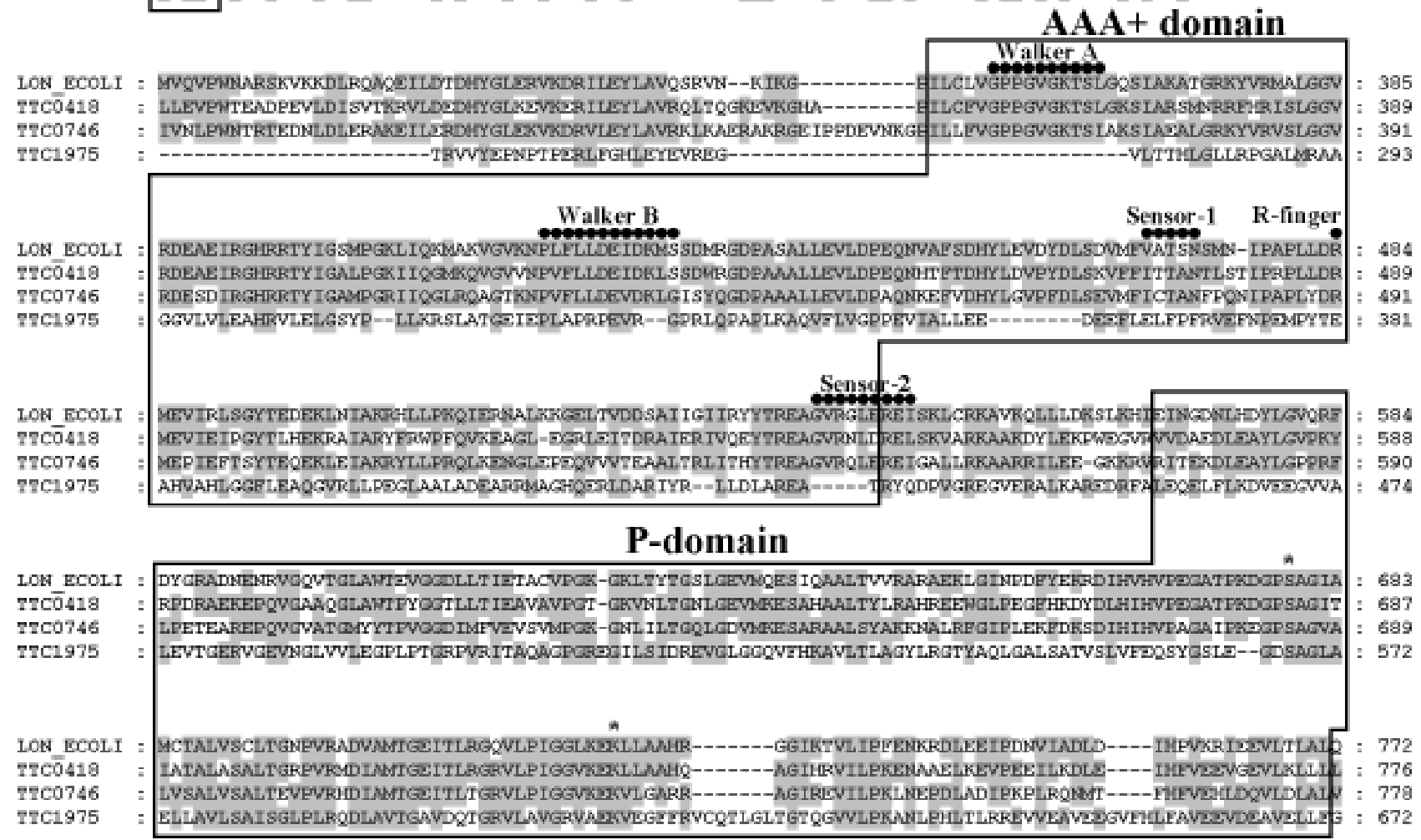

LON ECOLI : H-----EPSGMQVYTAK----- : 784

7?C0̄418; P-N-NPPPPAVQPDRPQPGVGA-- ; 795

IRC0746; GGLKALEERGRTRRSARTKKELLAHA ; 804

TIC1975 : RRAYWVHEKVREALEHFQKLDNGOSK ; 698

\section{Fig. 1a}




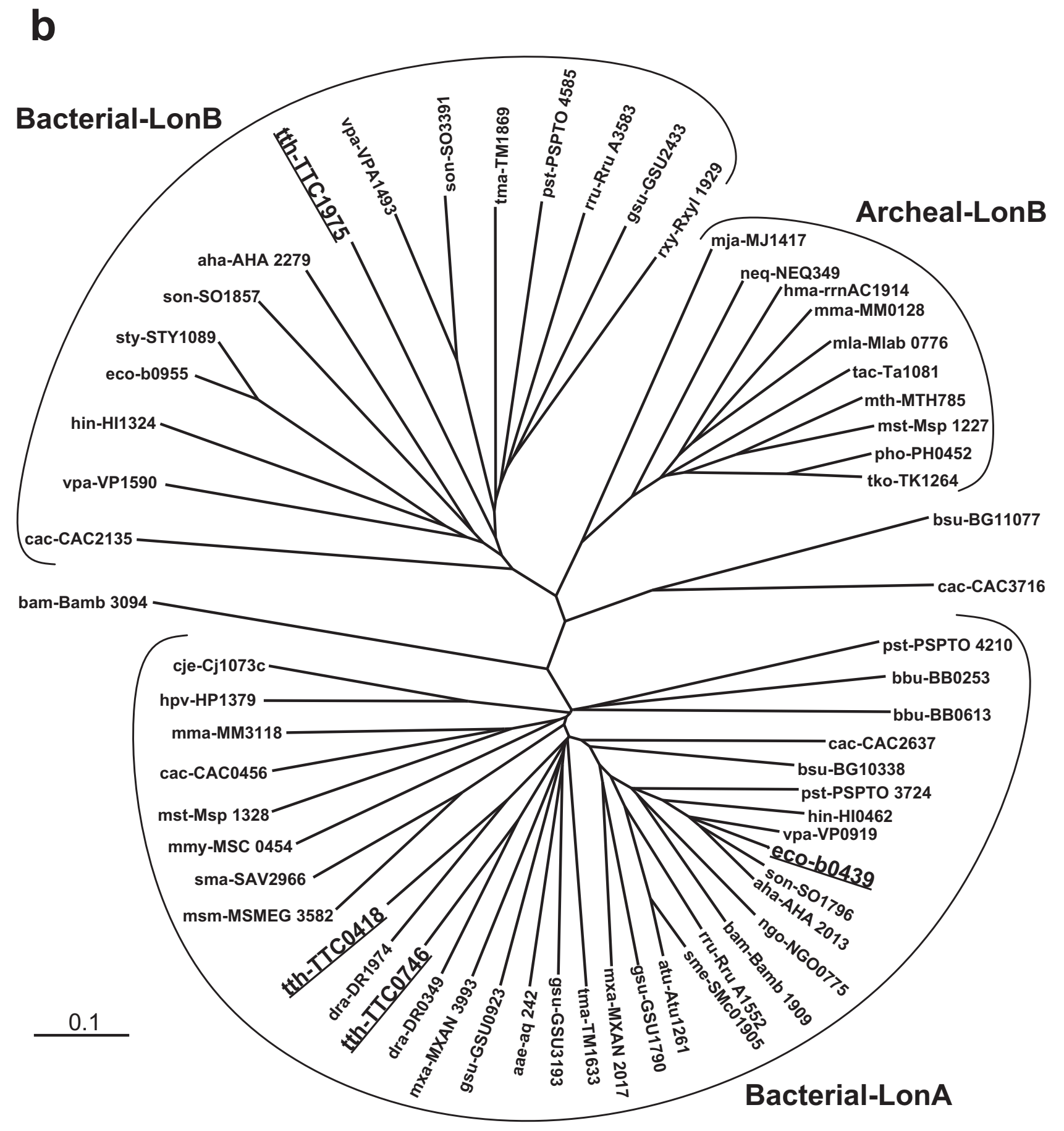

Fig. 1b 


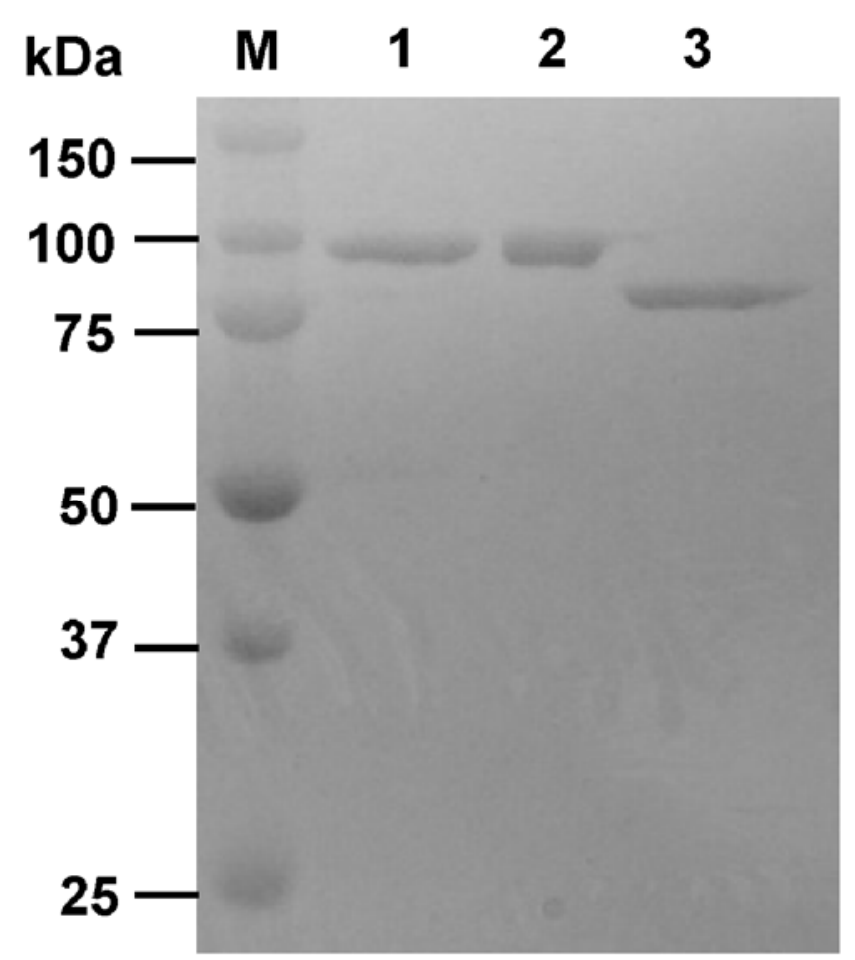

Fig. 2 


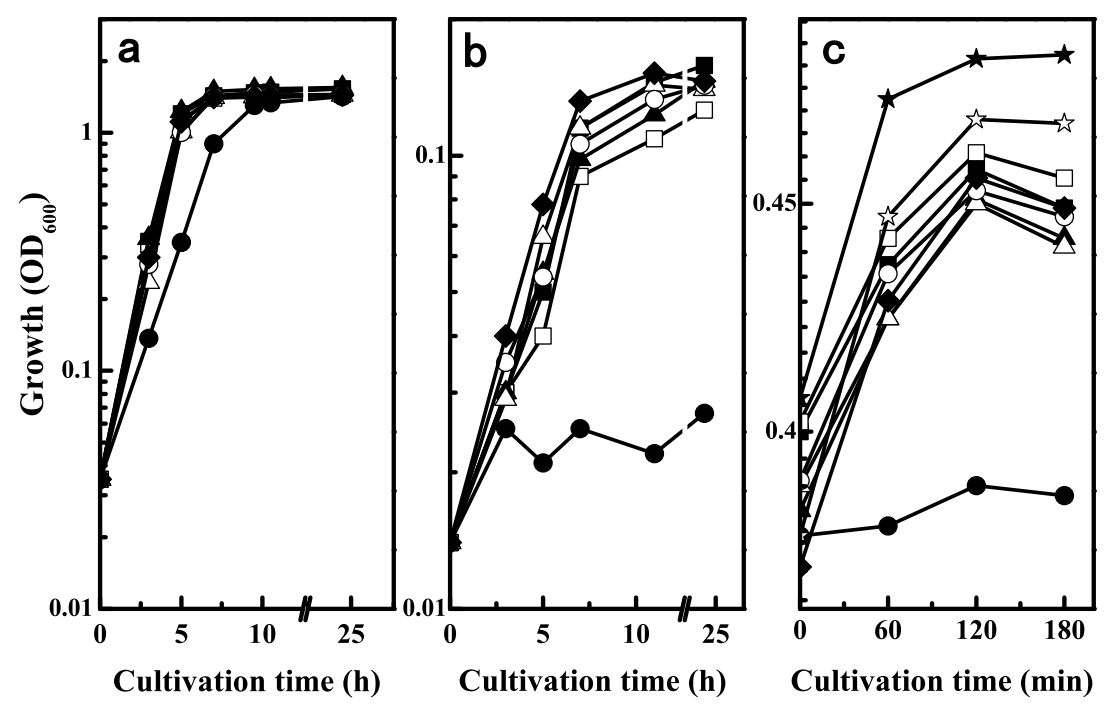

Fig. 3 